\title{
Médicos residentes e suas relações com/e no mundo da saúde e da doença: um estudo de caso institucional com residentes em Obstetrícia/G inecologia*
}

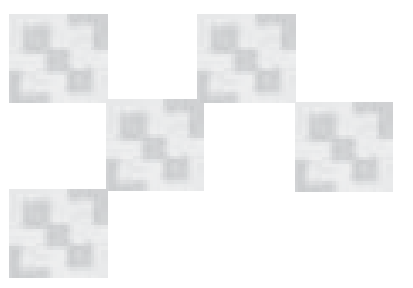

\author{
Ana Cristina Bohrer Gilbert ${ }^{1}$ \\ Maria Helena Cabral de Almeida Cardoso² \\ Susana Maciel Wuillaume ${ }^{3}$
}

GILBERT, A. C. B. ET AL. Medical residents and their relations with and within the health and illness environment: an institutional case study with Obstetrics/Gynecology residents. Interface - Comunic., Saúde, Educ., v.10, n.19, p.103-16, jan/jun 2006.

The perceptions of the physicians that completed their residency in Obstetrics/Gynecology in 2004 at the Fernandes Figueira Institute, of the Oswaldo Cruz Foundation, about their residency process are investigated. The research comprised two steps, participant-observation and the use of oral sources. The methodological procedure includes a qualitative analytical coding of the interviews and a subsequent semiotic analysis. The study aims at understanding the cultural heritage of the residents' discourses regarding their relations with and within the health and illness environment. Some of the elements discussed in this paper were: medicine as a depreciated profession; regret for the loss of the power of medical knowledge; the perception that medicine is seen more as a business than as a profession; the uncertainties of being simultaneously a professional and a student; the difficulties of getting in touch with the suffering and death of another human being.

KEY WORDS: internship and residency. profesional practice. medical education.

Investiga-se a percepção dos médicos que concluíram a residência em Obstetrícia/Ginecologia no Instituto Fernandes Figueira, Fundação Oswaldo Cruz, em 2004, sobre essa trajetória. A pesquisa constou de duas etapas, observação participante e construção de fontes orais, procedendo-se a uma codificação analítica qualitativa de todo o material coletado para posterior análise semiótica. Busca-se compreender a herança cultural enraizada no discurso dos residentes sobre suas relações com/e no mundo da saúde e da doença, em particular: desvalorização da profissão, ressentimento pela perda de poder do saber médico, percepção da medicina mais como negócio do que como ofício, incertezas pela duplicidade de papéis - aluno e profissional, dificuldade diante do sofrimento e da morte.

PALAVRAS-CHAVE: internato e residência. prática profissional. educação médica.

*Elaborado a partir de Gilbert (2005).

${ }^{1}$ Programa de Pós-Graduação em Saúde da Criança e da Mulher, Instituto Fernandes Figueira, Fundação Oswaldo Cruz, Fiocruz, RJ. <ana.gilbert@terra.com.br>

${ }^{2}$ Departamento de Genética, Instituto Fernandes Figueira, Fiocruz. <cardosomhca@uol.com.br>

${ }^{3}$ Departamento de Ensino, Instituto Fernandes Figueira, Fiocruz. <susanamaciel@wuillaume.com>

${ }^{1}$ Rua Voluntários da Pátria, 190/203

Rio de Janeiro, RJ

Brasil - 22.270-010 


\section{Introdução}

As relações entre o médico e o mundo que o cerca dizem respeito não apenas às estabelecidas com as pacientes e seu sofrimento e com outros profissionais, mas também àquelas que estabelece com o saber e o poder, o conhecimento, o tempo, o sofrimento e a morte. Tais relações trazem em seu bojo as influências do processo histórico de constituição da medicina e também aspectos míticos, cujo conteúdo faz parte do repertório psicológico e simbólico dos profissionais que escolhem essa profissão e da sociedade em geral.

Na residência médica, o treinamento envolve o aprimoramento do raciocínio clínico como instrumento da prática, por meio do qual se faz a articulação entre o caso individual e a teoria geral sobre as doenças. O olhar clínico que é apurado nesse treinamento vai além do sentido físico da visão, pois a ele são acrescidas as ferramentas das tecnologias de comunicação e biológicas, fatores fundamentais na modelagem dos corpos humanos, particularmente, dos corpos das mulheres, tradicionais alvos de visualização e intervenção (Haraway, 1997).

O conhecimento que é construído na residência, portanto, resulta de um processo de ensino-aprendizagem estruturado na prática, que tem na motivação um componente essencial para torná-lo significativo, no qual o residente é o agente e o preceptor, o mediador (Wuillaume, 2000). Ao estudar os discursos médicos de residentes, entende-se que são discursos especializados ainda em construção e busca-se elucidar o percurso da formação médica, não apenas em termos teórico-técnicos, mas também culturais, como lentes através das quais o médico dá significado ao mundo.

Para melhor equacionar essas questões, realizou-se um estudo de caso institucional (Yin, 2002) com residentes em Obstetrícia/Ginecologia do Instituto Fernandes Figueira (IFF), Fundação Oswaldo Cruz (Fiocruz), mediante duas etapas. Na primeira, fez-se uma observação participante de quatro reuniões da Ginecologia e quatro da Obstetrícia, registrando-se em notas de campo dados sobre: ambiente, relação entre os participantes, relação dos residentes com o staff, relação dos residentes com o caso narrado, aspectos rituais da apresentação de caso, construção do diagnóstico, construção de narrativas médicas, forma de lidar com situações não-rotineiras.

A seguir, tomando por base a análise dessas notas, foram construídas fontes orais utilizando-se o método elaborado e validado por Cardoso (1986), composto por quatro módulos de entrevistas, englobando contato prévio, história de vida, entrevista temática e depoimento livre e aberto. Foram trabalhados três tipos de memória que aparecem no decorrer dos módulos de forma entrelaçada: a individual, expressão de desejos, aspirações e conflitos; a coletiva, como forma de experiência de um grupo; e a histórica, como recordação de fatos.

Foram entrevistados sete dos oito médicos que estavam no último mês da residência Médica (janeiro de 2004) - cinco mulheres e dois homens -, pois um deles se encontrava em licença médica. Os depoimentos foram colhidos no próprio IFF, num período de quatro meses, com duração média de três horas e vinte minutos por pessoa, distribuídas pelos quatro 
módulos. Todos os depoimentos foram gravados e transcritos literalmente, de forma a permitir uma melhor análise. Por limite de espaço, neste artigo são trazidos alguns trechos ilustrativos do que foi ouvido, gravado e transcrito, tendo sido usadas siglas para nomear os entrevistados, a fim de preservar suas identidades.

O material coletado passou por uma codificação qualitativa para identificar os temas de interesse. A seguir, procedeu-se a uma análise semiótica, que considerou aspectos como: a coerência e competência textuais e intertextuais, as estruturas superficiais e profundas do texto, isto é, a forma como os significados são colocados em discurso, e o processo de "discursivização", que compreende a "actorialização" (estabelecimento dos personagens no discurso), "temporalização e espacialização" (efeitos do tempo e do espaço), "tematização" (a geração dos elementos abstratos) e "figurativização" (o aparecimento dos elementos concretos) (Cardoso, 1997).

A pesquisa foi aprovada pelo Comitê de Ética em Pesquisa do IFF, sob o parecer no. 054/03, de 04 de dezembro de 2003 e financiada pela CAPES, compondo, também, dissertação de mestrado defendida no Programa de Pós-Graduação em Saúde da Criança e da Mulher do IFF/ Fiocruz (Gilbert, 2005).

O texto que se segue, partindo das experiências vividas nos dois anos de residência médica, focaliza as relações dos médicos em processo de formação especializada em Obstetrícia/Ginecologia com: o saber e o poder, o conhecimento, o tempo, e o sofrimento e a morte.

\section{O saber e o poder}

Os homens, em seu anseio por explicar os fenômenos que os cercavam e por elaborar e expressar aquilo que não conheciam, criaram e se utilizaram de mitos, explicações mágicas ou sobrenaturais, que constituíram os primórdios do conhecimento sobre eles próprios e o mundo. Assim o foi também em relação à medicina, ao que seria saúde e doença, estabelecendo analogias entre corpo e natureza e seus processos (Castoldi, 1996).

É a partir de Hipócrates de Cós que a medicina ganha contornos mais científicos e menos mágicos no que se refere ao entendimento das doenças. Os conceitos gregos sobre saúde e doença são ampliados por Galeno, no século II, e permanecem dogmáticos por cerca de 14 séculos (Castoldi, 1996).

No final do séc. XVIII, dois grandes ideais associados ao exercício da Medicina se estabelecem: o do poder médico, equivalente ao poder clerical, e o da eliminação da doença, resultado de uma sociedade cujo controle médico ajudou a organizar (Foucault, 2003).

Saber e poder se implicam mutuamente. A partir do séc. XIX, o hospital torna-se mais que um local de cura, transformando-se num espaço onde o saber é produzido, acumulado e transmitido e, conseqüentemente, onde o poder é exercido. O conhecimento fisiológico, antes mantido à margem para o médico, torna-se o centro de toda sua reflexão. Passa a ocupar o papel de organizador do espaço das moradias e das cidades e a estabelecer as regras para a sociedade, significando, em termos políticos, uma legitimação 
da Medicina pelo Estado (Foucault, 1990), e fornecendo as bases para que o governo possa pensar medicamente os problemas da população, tais como: delinqüência, criminalidade, indigência (Rose, 1999).

O poder está presente nas relações humanas de modo geral e também na hierarquia organizacional dos serviços hospitalares. O poder não é algo que se possui ou não, mas é exercido em relações constituídas historicamente. Nesse sentido, o que existe são práticas ou relações de poder configuradas em teia, que comporta os movimentos de resistência a essas mesmas práticas ou relações (Foucault, 1990).

Em nossa cultura, a relação do médico com o paciente é assimétrica, calcada na presença do conhecimento no primeiro e na ausência, no segundo. Assimétrica se conforma também a relação do residente com os membros da equipe à qual se integra quando do início da residência.

No hospital, o residente é aquele que acaba de ingressar num período de especialização com caráter de um rito de passagem, por constituir uma transição de um nível de status para outro: de aluno para profissional. Entretanto, esse profissional, até bem pouco tempo aluno do sexto ano de medicina, patamar mais alto na hierarquia do alunado, passa agora a ocupar o mais baixo na hierarquia da profissão dentro do hospital, o de R1. Essa queda é muito rápida e acarreta ressentimentos. Inicialmente, a rotina do serviço é desconhecida, assim como características da própria especialidade. Mas por ser médico, talvez haja a ilusão da primazia do território, o qual pode ser entendido tanto como o espaço do hospital, quanto o corpo da própria paciente adoecida. O iniciar da residência traz uma excitação antecipatória que é substituída aos poucos por períodos de insegurança e depressão, alternados com sentimentos de competência e arrogância ao final do primeiro ano (Martins, 1994).

O peso da responsabilidade por lidar intimamente com o binômio vida e morte é o primeiro aspecto salientado nos depoimentos analisados, que sem dúvida remete à questão das relações de poder. Conforme expressa S4: “Quando algo complica, o medo que dá é da morte. Por um lado, um poder muito grande, de salvar; por outro, uma impotência também grande, quando dá errado".

A influência da medicina, enquanto discurso e prática que detém um domínio sobre a forma como os indivíduos pensam, moldam e vivem seus corpos, implica, em sua gênese, uma teorização e materialização destes corpos como textos codificados, requerendo de quem os pretende conhecer, em seus múltiplos órgãos e sistemas, um conhecimento altamente especializado que o legitime como "decifrador".

A noção de "ferimento", presente no curador mítico Quirão, como aquilo que o aproxima dos mortais, do sofrimento do outro, por ser capaz de saber/sentir a dor, aparece como metáfora latente nas narrativas escutadas, sob a forma de adoecimentos reais que marcam indelevelmente os residentes, confrontando-os com sua vulnerabilidade e incapacidade de tudo decifrar e, assim, curar, trazendo a noção de limite. Como disse S3, recordando ter ficado enferma no início da residência: "[O médico] me deu uma licença que eu não cumpri e por isso até piorei. Não queria parar de trabalhar, não queria me sentir doente". S5 também, com toda clareza, 
expõe: "Foi o [sofrimento do outro] o que mais me chocou. Eu me cobrava muito de ter que dar conta".

Evocar o mito não significa tomá-lo no sentido literal, mas perceber que o real e o ficcional, o científico e o mítico interagem e compõem o arcabouço cultural de determinada sociedade, incluídas as percepções e práticas leigas acerca das doenças e opiniões e valores sobre o próprio médico. S7 corrobora essa assunção ao lamentar: “A profissão de médico agora é uma profissão comum, sem mito, sem idolatria; falta poder, sobra contestação".

Barthes (2001) define o mito contemporâneo como metalinguagem, cuja função é esvaziar o real de história, transformá-lo em natureza de forma a retirar o seu sentido humano e torná-lo eterno. O mito é um sistema de comunicação, uma fala, um modo de significação. Ele não esconde nem chama a atenção para si: o que faz é deformar o sentido, pela naturalização do conceito. Percebe-se uma mudança da percepção do médico com significados relacionados a um sacerdócio (Castoldi, 1996), para a de pessoas como outras quaisquer, inseridas em uma realidade contextual, com sérios problemas e dificuldades para exercer a profissão.

O limite ainda se revela pela declarada falta de conhecimento, quando comparada ao de um profissional mais experiente, mesmo que não-médico e ainda que social e institucionalmente posicionado em situação inferior. Aparece também sob a forma de uma identificação com a paciente, gerando angústia pela incapacidade, ainda que momentânea, de se perceber diferente e separado do outro. Ou se manifesta por intermédio da queixa de que, atualmente, a grande difusão de informações médicas veiculadas pelos meios de comunicação, paulatinamente, promove uma perda da exclusividade do saber, alterando as relações com as pacientes, que passam a questionar, a testar e até desrespeitar o diagnóstico e a terapêutica. A percepção geral é a de que, se por um lado, como diz S7, não há mais a aceitação do peremptório: "sou o médico; sou o dono da verdade", por outro, a sensação de ser perenemente testado acaba por pautar, conforme também afirma o mesmo depoente, o "tem que me respeitar", porque o saber especializado, tal como o do decifrador de códigos profissional, é inquestionável e percebido como auferido e legitimado pelos anos de estudo e, agora, de prática numa determinada especialidade da Medicina.

Nos relatos analisados, as relações entre saber e poder também se refletem nas afirmações acerca das responsabilidades do médico no setor público e no privado. No primeiro, elas são consideradas mais diluídas do que no segundo, em função da existência de uma relação não muito próxima com a paciente, e também em razão do desnível sociocultural assumido como fato no mundo. Na clínica privada, a noção geral é de que a cobrança é sistemática, inclusive, implicando uma prática da medicina fatalmente cada vez mais defensiva, pois conforme se queixa S6: “Hoje em dia, tem a indústria do processo".

Para todos os residentes entrevistados, o poder, além de sua articulação com o saber, vincula-se à capacidade de "convencimento" da paciente, por parte do médico, da veracidade desse saber, o que, por sua vez, assenta-se na boa relação entre eles. O poder de convencer é proporcional à capacidade 
de elaborar uma boa relação médico-paciente, vista como condição sine qua non para atingir o não-questionamento e a concordância. Todavia, o que não é verbalizado resta subjacente, pois atingir este escopo só é possível porque ambos, médico e paciente, compartilham a mesma asserção cultural que legitima o domínio hierárquico do saber científico (Villar \& Cardoso, 2002), como produtor absoluto da verdade.

\section{O conhecimento}

A busca do conhecimento, em especial na residência, por ser um período de construção de uma identidade profissional, é direcionada primordialmente aos profissionais da instituição, por conjugarem informação e experiência. Para todos, o fundamental não é ter uma fonte teórica, mas de acordo com S3: "discutir com um profissional mais experiente".

O estudo é guiado pelas dúvidas que surgem diante de situações reais na rotina do atendimento. Contudo, nos casos mais complicados de ambulatório, onde o tempo não é decisivo, os livros ou artigos são citados como podendo ser consultados com mais calma, para o esclarecimento de uma situação específica.

O conhecimento teórico e a observação clínica, reiterando, se complementam: não é possível considerar apenas um deles. É a narrativa codificada, construída com base no relato da paciente, que faz a conexão entre os dois, confrontada com os sinais mostrados pelo corpo e com o resultado dos exames complementares.

Segundo Camargo Jr. (2003), no processo de seleção de informação considerada relevante e/ ou confiável, por parte dos médicos, parece existir uma estratégia, que ocorre de forma mais intuitiva e menos consciente e sistemática, de reconhecimento de sinais, semelhante à empregada ao diagnosticar, que agrupa os elementos significativos, formando uma gestalt. Entretanto, existe uma falta de recursos para avaliação dessa informação, devido à escassez de tempo e ao desconhecimento, em especial de epidemiologia e estatística, que possibilite uma discussão dos métodos empregados nas pesquisas. Assim, a relevância da fonte acaba sendo estabelecida, freqüentemente a priori, pela sua credibilidade acadêmica, pela vinculação à prática clínica, ou ainda por serem previamente digeridas e selecionadas pela indústria médico-farmacêutica.

A medicina baseada em evidências, um dos desdobramentos das tecnobiociências, no discurso dos entrevistados, ganha conotação de uma âncora para a prática clínica, por ser entendida como fundamental à atualização do conhecimento, uma vez que, como diz S3, ela demonstra o que "funciona ou não no paciente [pois é] evidência de uma prática". Essa definição tautológica é acrescida de declarações sobre situações geradoras de dúvida e insegurança, que evidenciam as duas vertentes da medicina, a ciência e a arte (Castoldi, 1996), trazendo a impossibilidade de se conciliar o caráter geral da teoria das doenças com as singularidades das pacientes. S4 reitera essa divisão entre o individual e o geral, ou, em outras palavras, a definição clássica de medicina como ciência e arte, ao afirmar: "Medicina não é regra, nunca foi. Cada caso é um caso".

A atual dificuldade de absorção dos profissionais médicos pelo mercado 
de trabalho, já na residência, aliada ao aumento do número de cursos de medicina de qualidade duvidosa (Pessoa \& Constantino, 2002) estabelece, para os entrevistados, a especialização como difer encial. Nesse afunilamento crescente, a opção por uma carreira acadêmica, que inclui mestrado e doutorado, também aparece como atrativa, exceto para aqueles que se reconhecem como essencialmente voltados para a prática clínica. Nesse sentido, S6 assevera que: "Não tem como a parte acadêmica superar a parte do atendimento, quando você não tem prática nenhuma". E acrescenta: "Não adianta ter um mundo de informação acadêmica se quando vai para o consultório, para outro hospital, você não tem experiência".

A residência é vista também como uma forma de ganhar mais segurança, diante de uma complexidade crescente das especialidades. A noção que se patenteia é a de que, ao se restringir o campo de atuação, circunscreve-se melhor o conhecimento a ser atualizado. O argumento apresentado por todos é que tal recorte traz, inclusive, mais segurança para a paciente, apesar da reconhecida conseqüente compartimentalização. A formação generalista é tida como um retrocesso, sendo desvalorizada e percebida como caminho somente percorrido por aqueles que não conseguiram ser admitidos como residentes em hospitais credenciados, uma vez que, conforme também diz S6: "Porque quanto mais você se subespecializa, a tendência é que você saiba mais sobre aquele assunto. Lógico que o paciente ganha". Mas, ele também reconhece que: "Talvez essa parte para a paciente seja ruim, o ter que procurar mais médicos: ela ganha na qualidade e perde um pouco na relação".

\section{O tempo}

A questão do tempo permeia todos os depoimentos: a sua falta, dificultando a atualização diante do volume crescente de novas informações, necessidade característica do estilo de pensamento clínico (Camargo Jr., 2003); a opção pela não-exclusividade da medicina na vida, com priorização do aspecto pessoal e afastamento da visão da medicina como sacerdócio; nas escolhas em Obstetrícia, especialidade muito ligada ao tempo, claramente expresso no trabalho de parto e na crescente opção por cesariana como forma de melhor administrá-lo, e que traz uma sensação de maior controle dos riscos envolvidos no parto.

É por meio das relações que o homem estabelece em sociedade (entre elas a relação com o tempo) o que vai significar sua vida (Augusto, 1994). A emergência da noção de indivíduo é contemporânea ao processo desenvolvido no século XVIII e início do século XIX. Nela está embutida a crença no progresso contínuo, linear, ilimitado, guiado pela razão e realizado por intermédio do desenvolvimento da ciência e da tecnologia, assim como a esperança no controle da natureza, administrada pela fé na capacidade do homem de liberdade e de escolha.

A residência é encarada como um período iniciatório marcado pela cobrança e extenuante rotina (Cousins, 1981) que o residente deseja completar para adquirir instrumentos legitimadores de poder, tais como o raciocínio clínico mais apurado e o "pegar mão", significando habilidade 
cirúrgica.

Nessa rotina, são apontados como fatores estressantes, por diversos autores (Martins, 1994): a fadiga pela grande carga de trabalho, despertando sentimentos hostis em relação a vivências de exploração e desrespeito; a falta de tempo para a vida pessoal; a responsabilidade no atendimento aos pacientes, trazendo o medo de cometer erros, e a falta de conhecimento e experiência, que ameaçam a autoconfiança. Tais fatores requerem o desenvolvimento de reações adaptativas por parte do organismo, todos foram confirmados pelos residentes em seus depoimentos.

A vulnerabilidade psicológica do médico é considerada um tema delicado (Nogueira-Martins \& Jorge, 2004), que se apresenta em função das pressões inerentes à profissão, na lida diária com vida, doença e morte; pelo contato íntimo com o corpo do outro, com suas queixas, reivindicações, submissão e hostilidade; pelas incertezas da medicina, especialmente, num hospital terciário e de ensino, onde a gravidade dos casos é maior em relação aos hospitais gerais. Apesar da Obstetrícia/Ginecologia ser considerada pelos entrevistados uma especialidade mais ligada à vida do que à doença e, conseqüentemente, à morte, no IFF ela envolve casos graves, especialmente a Obstetrícia, provocando um impacto inicial e uma angústia muito grande nos residentes.

Observa-se um movimento no sentido de estabelecer limites para a vida profissional, com uma tendência a migrar para subespecialidades que permitam uma rotina com horários mais regulares e o contato com a paciente mediado pela tecnologia, como é o caso do diagnóstico por imagem e vídeo (laparoscopia e histeroscopia). Esta escolha está associada à atração que a tecnologia de imagem exerce, por disponibilizar procedimentos menos invasivos e que representam uma fonte de segurança, mas também, à inclinação para o distanciamento do eixo conjetural da medicina, já que a imagem é tida como capaz de mostrar mais e melhor e ser fiel reprodução do que, na verdade, representa.

São identificados quatro grupos de fatores ligados à pressão do tempo (Martins, 1994) que, associados, podem provocar situações de fadiga e exaustão, e que devem ser considerados nos programas de residência: a) a pressão social característica da assistência; b) a pressão dos valores, que envolvem o ser médico; c) a pressão advinda do aprendizado, e d) a pressão que surge em função das necessidades do residente.

A pressão social refere-se a uma ampla discussão sobre a residência como período de preparação do profissional e/ou uma exploração do jovem médico (Cousins, 1981). Para os residentes entrevistados, o volume de atendimento é grande, gerando ansiedade em distribuir o tempo e, muitas vezes, causando problemas com a marcação das agendas. Esse tempo escasso, segundo eles, também impede a existência de um espaço de discussão dos aspectos não fisiológicos dos casos, e mesmo relativos à vivência da residência, com todas as dúvidas e questionamentos pertinentes, pois a máxima parece ser a apontada por S2: "Residente não fica cansado".

A ausência desse tipo de discussão envolve outros fatores, como 
competição, demonstração de poder, idealização da profissão, que permeiam o segundo tipo de pressão do tempo: a dos valores, que colocam o médico numa posição privilegiada em termos de atuação sobre a vida e a morte, mas que o pressionam no sentido de não cometer erros e de ter de decidir em situações emergenciais o que, para um residente, ainda em processo de construção de confiança e identidade, pode significar um peso excessivo. Existe o receio de ficar sozinho num plantão, como assumidamente declara S5: "Eu tenho medo da emergência, de chegar uma paciente com a vida na minha mão e eu não conseguir resolver".

A terceira forma, a do aprendizado, inclui os conflitos inerentes ao ser aluno e profissional simultaneamente, e o ter de adquirir conhecimento especializado em pouco tempo. Ora lhes é cobrado que sejam capazes de tomar iniciativas, ora Ihes é lembrada a condição de dependência de um profissional mais experiente, do qual devem apenas seguir as instruções. 0 conflito polariza sentimentos, fazendo-os oscilar entre a insegurança e a segurança exacerbadas. Como fala S1, Ihes é dito: "vocês são residentes, estão aqui para cumprir ordens"; e no momento seguinte, Ihes é cobrado: "Vocês não têm discernimento?".

Durante as entrevistas, o carimbo levado no bolso do jaleco por todos os entrevistados, metaforicamente representando a aquisição da responsabilidade e o status de médico, serviu como indicador desses momentos de mais insegurança, sob a forma de um constante batê-lo contra a mesa, que ganhava aceleração quando o tema sugeria algo crítico, que extrapolava o domínio ou controle.

A quarta forma de pressão do tempo, a das necessidades do residente, refere-se a uma expectativa ilusória inicial de tornar-se o especialista completo, seguro e experiente, e que vai se transformando de forma a reconhecer os ganhos reais, mas também a perceber que é apenas uma etapa que foi cumprida, que ainda há um longo caminho a ser percorrido, pois, conforme reflete S2, parecendo recitar um credo: "as coisas vão num contínuo".

\section{O sofrimento e a morte}

A dificuldade de estar em constante contato com o sofrimento do outro e a necessidade de realizar determinadas intervenções exigem do médico uma dissociação das representações que ele tem sobre os órgãos e sobre o corpo em geral, mas que pode chegar a uma "coisificação" da paciente. Esse aprendizado é sentido pelos residentes como paulatino, pelo contato rotineiro com a dor e a doença.

No contato com o sofrimento do outro, ouvir se diferencia de escutar: o primeiro refere-se a um fenômeno fisiológico, enquanto o segundo, a um fenômeno psicológico. Nesse percurso de predominância do olhar ampliado sobre os outros sentidos, percebe-se que a escuta que ocorre, na maioria das vezes, é a descrita por Barthes (1990) como uma escuta que busca "Ier" os signos, tendo como referência códigos já estabelecidos. No caso do médico obstetra/ginecologista, ele é capaz de ver o interior do corpo da mulher, portanto, é capaz de decifrar e saber. E para ver melhor ou decifrar melhor, ele a escuta, buscando identificar sinais relevantes que o orientem 
em sua formulação do diagnóstico. O foco nesse tipo de escuta é sobre o que é dito pela paciente e não a própria paciente.

Como categoriza S6, com pacientes consideradas "queixosas", que "gostam de fazer drama", e em quem, segundo ele, não existe uma vontade real de melhorar, a escuta é prejudicada, por gerar certa impaciência no médico, que passa a desconsiderar as informações trazidas. Os residentes consideram que a mulher vem ao ginecologista por questões que vão além do mal-estar físico, confrontando-os com o limite e a dificuldade de atuar em algo que extrapola a especialidade. De acordo com eles, cabe à sensibilidade de cada um identificar essas situações e discriminar o que deve ser levado em consideração, o que reconhecem nem sempre acontecer, pois, de acordo com as palavras de S1: "É uma coisa meio pessoal".

Para os depoentes, essa sensibilidade aparece como sendo algo inerente, e que vai sendo desenvolvida no decorrer do aprendizado profissional. Entretanto, queixam-se de que é pouco estimulada ou discutida no programa da residência médica ou, mesmo, na graduação. Segundo eles, Ihes é cobrado que a considerem dissociada do raciocínio baseado em sinais ou evidências concretas, só sendo permitida e valorizada em profissionais mais experientes.

Cabe assinalar, entretanto, que essa sensibilidade é indissociável do próprio conhecimento médico que, apesar das ilusões ao contrário, sempre expressa elementos intuitivos, inclusive, percepções físicas, que associados à criatividade e à analogia, compõem o processo diagnóstico, montado a partir das informações semiologicamente coletadas e confrontadas com a grade nosológica de referência (Castiel, 1999).

No que se refere à morte, até o final do séc. XVIII, o olhar médico é voltado para a eliminação da doença, a cura e a restauração da vida; a morte está fora do alcance desse olhar e desafia o conhecimento e a habilidade do médico. Com Bichat, anátomo-patologista (Foucault, 2003), os olhos do médico se voltam para a morte, buscando nela as respostas do seu fracasso, as explicações para a doença e para a vida, libertando a medicina do medo da morte, que foi integrada num quadro técnico-conceitual, com características determinadas e relevância como experiência.

A cultura realiza um trabalho de classificação da morte para melhor compreendê-la e para dar-Ihe sentido, resultando numa série de práticas, teorias, dogmas e idéias (Rodrigues, 1983). A morte, tal como a conhecemos hoje, nasce junto com o processo de valorização do indivíduo. Ela perde o conteúdo de festividade e coletividade para dar lugar à individualidade e à angústia diante dela, passando a ser evitada mediante a sua naturalização. Ao acreditar-se capaz de controlar a natureza por meio da ciência, o homem sente-se capaz de fazê-lo em relação à morte, que passa a ser vista como fracasso do corpo e da atenção médica (Pitta, 1994). Para Foucault (1990), essa esquiva da morte acontece pela mudança de foco da ação do poder, que passa a se fixar sobre a vida, por intermédio de mecanismos de regulação e correção, desembocando numa sociedade normalizadora.

Culturalmente, os médicos são vistos como inimigos da morte, à qual 
deverão vencer. A metáfora da batalha é bastante presente na medicina e nela o médico é aquele que disputa, com a doença e a morte, a posse pelo paciente. A doença pode ser entendida como oscilando entre algo que é externo e penetra no corpo, e algo que é interno e causa um desequilíbrio no organismo. Essas imagens são recorrentes em todas as narrativas feitas pelos residentes. Para eles, nitidamente, o corpo da paciente é o território, e se um câncer aparece, conforme fala S6: o "querendo ocupar" o médico tem de expulsá-lo, porque, segundo ele: "O médico sempre quer vencer; não quer ser vencido".

Segundo Canguilhem (2002), a vida se caracteriza como polaridade que se contrapõe a tudo o que pode ser considerado um empecilho para a normatividade biológica, entendida como toda atividade que é própria do organismo. Cabe à medicina atuar na mesma direção, prolongando esse esforço espontâneo de defesa e luta que é próprio da vida.

Entretanto, isso nem sempre é possível, devendo o médico desenvolver mecanismos para superar a frustração do fracasso e a impotência daí advinda. A residência configura-se como um aprendizado, no sentido dado por S4 de: "ter que lidar com o sofrimento das pessoas, com a morte". Não há nada que apague da memória o primeiro paciente que se vê morrer, mas depois, a morte torna-se tão rotineira que se passa a considerar que, se a cura não foi alcançada num paciente, virão outros, visto que, como diz S4: "Você tem tantas outras pessoas para ajudar".

A análise dos depoimentos indicou que não é o contato com a morte, como conceito abstrato, o que é mais difícil, mas acompanhar o paciente vivo que está morrendo (Zaidhaft, 1990). Os sentimentos de culpa são reavivados, colocando os residentes, como qualquer outro ser humano, frente a frente com a possibilidade de sua própria morte e limitação (Cousins, 1981), levando-os muitas vezes a atitudes de obstinação para conseguir a cura da doença (Pitta, 1994).

\section{Considerações finais}

Para os residentes, a medicina tem se tornado mais um negócio do que um ofício. Segundo eles, ainda existe no imaginário social a noção de que o médico realiza um trabalho que não deveria ser cobrado. A realidade para quem está começando, afirmam, é a de uma profissão que é cada vez mais banalizada, apesar da responsabilidade de lidar com vidas humanas, na qual se ganha pouco e se trabalha muito. A assimetria existente entre médico e paciente, pautada no conhecimento, não é estática: percebe-se o movimento, interno a essa mesma relação, de resistência que exerce tal pressão sobre o médico que faz pender a balança para o pólo oposto.

Começar com uma atividade de consultório é difícil, não só em termos de clientela, mas devido à insegurança do trabalho solitário. Integrar uma equipe com profissionais mais experientes que possam dar orientação é percebido como uma forma paulatina de ganhar confiança. Os concursos para os hospitais públicos são outra porta de entrada no mercado, agora que deixam a segurança da residência.

Torna-se negócio também pela questão dos planos de saúde, que ditam regras em áreas que tocam a responsabilidade ética do médico, como nos 
atendimentos em hospitais, diante de situações graves, onde a falta de cobertura para determinados procedimentos é uma constante. 'O que fazer?' perguntam-se os residentes. Respeitar as normas administrativas e colocar em risco o registro no CRM ou seguir o que manda a ética médica? Essa é uma questão que, para eles, permanece aberta, sem resposta.

O saldo final da residência aparece como positivo, apesar das reclamações quanto à falta de mais parte prática ou de mais parte teórica; dos casos difíceis e angustiantes que se apresentam num hospital com o perfil do IFF, e dos eventuais problemas de relacionamento com a equipe. Todos reconhecem a bagagem adquirida nos dois anos da residência e se percebem capazes de enfrentar situações fora do ambiente protegido do hospital, apesar dos receios, da consciência de não saber tudo.

Vários estudos apontam para a necessidade de mudanças no ensino da medicina e sugerem a busca de novas perspectivas de se relacionar com o paciente, articulando melhor clínica e teoria. Alguns propõem a introdução do ensino de humanidades (Carson, 2000) e da Bioética, de forma a ampliar o olhar do estudante, bem como suscitar o questionamento do modelo passivo ensino-aprendizagem (Rodríguez et al., 2004; Siqueira e Eisele, 2000).

Mas talvez a questão seja mais profunda do que o acréscimo de informação; talvez falte abrir arenas de discussão, não apenas para aprender sobre novas tecnologias diagnósticas e terapêuticas, mas para refletir sobre o processo de construção de identidade profissional do médico. Nesse processo, encontram-se inseridos o desenvolvimento da competência narrativa, a importância da sensibilidade no aprimoramento do raciocínio clínico, as dúvidas e inseguranças inerentes à transição entre aluno e profissional e, principalmente, as teias de relações nas quais se encontram envolvidos médicos e pacientes como seres históricos, pertencentes a um contexto cultural específico, compartilhando valores, conceitos, padrões que estão presentes e atuantes, ainda que de forma subliminar, no momento da consulta. Também é preciso pesar o saber e o poder, na moldura da administração dos corpos sociais e individuais, comprometendo-se responsavelmente com diferentes saberes e entendendo que a questão do poder não é executá-lo sobre os outros, e que ele pressupõe a liberdade como questão constitutiva de todas as práticas, tal como a médica que, historicamente, vêm tecendo as relações humanas.

\section{Referências}

AUGUSTO, M. H. O. Tempo e indivíduo no mundo contemporâneo: o sentido da morte. Psicologia USP, v.5, n.1/2, p.157-172, 1994.

BARTHES, R. O óbvio e o obtuso. Rio de Janeiro: Nova Fronteira, 1990.

BARTHES, R. Mitologias. Rio de Janeiro: Bertrand Brasil, 2001.

CAMARGO JR., K. R. Sobre palheiros, agulhas, doutores e o conhecimento médico: o estilo de pensamento dos clínicos. Cad. Saúde Pública, v.19, n.4, p.1163-74, 2003.

CANGUILHEM, G. O normal e o patológico. Rio de Janeiro: Forense Universitária, 2002. 
CARDOSO, C. F. Narrativa, sentido, história. Campinas: Papirus, 1997.

CARDOSO, M. H. C. A. Programa de história oral: os quatro módulos: método e prática. Hist. Cad., v.4, n.1, p.29-35, 1986.

CARSON, R. A. The formation of medical imagination. Rev. Bras. Educ. Med., v.24, n.1, p.31-5, 2000.

CASTIEL, L. D. A medida do possível... saúde, risco e tecnobiociências. Rio de Janeiro: Fiocruz/ Contra Capa, 1999.

CASTOLDI, M. A. Tornar-se pediatra: o desenvolvimento do raciocínio clínico na residência médica do IFF. 1996. Dissertação (Mestrado) - Instituto Fernandes Figueira, Fundação Oswaldo Cruz, Rio de Janeiro.

COUSINS, N. Internship: preparation or hazing? JAMA, v.245, p.377, 1981.

FOUCAULT, M. Microfísica do poder. Rio de Janeiro: Edições Graal, 1990.

FOUCAULT, M. O nascimento da clínica. Rio de Janeiro: Editora Forense Universitária, 2003.

GILBERT, A. C. B. A hora instável entre mãe e mulher. Um estudo com residentes em Obstetrícia/Ginecologia do IFF/FIOCRUZ. 2005. Dissertação (Mestrado) - Instituto Fernandes Figueira, Fundação Oswaldo Cruz, Rio de Janeiro.

HARAWAY, D. Pragmatics. Technoscience in hypertext. In: Modest_Witness@SecondMillenium. FemaleMan@_Meets_OncoMouse ${ }^{\mathrm{TM}}$. New York: Routledge, 1997. p.125-65.

MARTINS, L. A. N. Residência médica: um estudo prospectivo sobre dificuldades na tarefa assistencial e fontes de estresse. 1994. Tese (Doutorado) - Escola Paulista de Medicina, São Paulo.

NOGUEIRA-MARTINS, L. A.; JORGE, M. R. Natureza e magnitude do estresse na residência médica. Rev. Assoc. Med. Bras., v.44, n.1, p.28-34, 1998.

PESSOA, J. H. L.; CONSTANTINO, C. F. O médico residente como força de trabalho. Rev. Soc.

Cardiol. Estado de São Paulo, v.12, n.6, p.821-5, 2002.

PITTA, A. Hospital: dor e morte como ofício. São Paulo: HUCITEC, 1994.

RODRIGUES, J. C. 0 tabu da morte. Rio de Janeiro: Achiamé, 1983.

RODRIGUEZ, C. A.; POLI NETO, P. P.; BEHRENS, M. A. Paradigmas educacionais e a formação médica. Rev. Bras. Educ. Med., v.28, n.3, p.234-41, 2004.

ROSE, N. Medicine, history and the present. In: JONES, C.; PORTER, R. (Eds.) Reassessing

Foucault: power, medicine and the body. London: Routledge, 1999. p.48-72.

SIQUEIRA, J. E.; EISELE, R. L. O ensino da ética no curso de medicina. Rev. Bras. Educ. Med., v.24, n.1, p.22-6, 2000.

VILLAR, M. A. M.; CARDOSO, M. H. C. A. Residência médica em pediatria: no campo da prática. Cad. Saúde Pública, v.18, n.1, p.329-39, 2002.

WUILLAUME, S. M. O processo ensino-aprendizagem na residência médica em pediatria: uma análise. 2000. Tese (Doutorado) - Instituto Fernandes Figueira, Fundação Oswaldo Cruz, Rio de Janeiro.

YIN, R. K. Case study research. Design and methods (applied social research methods). London: Sage Publications, 2002.

ZAIDHAFT, S. Morte e formação médica. Rio de Janeiro: Francisco Alves, 1990. 


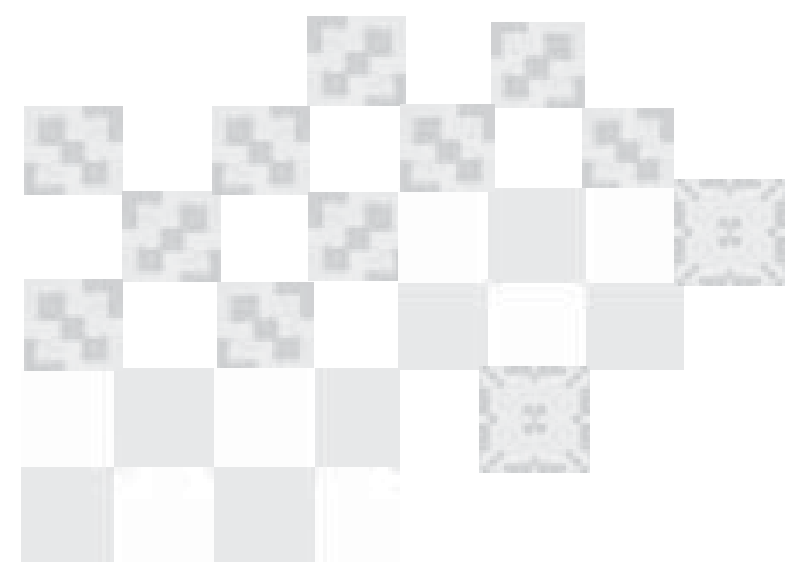

GILBERT, A. C. B. ET AL. Médicos residentes y sus relaciones con y en el mundo de la salud y la enfermedad: un estudio de caso institucional con residentes en Obstetricia/ Ginecología. Interface - Comunic., Saúde, Educ., v.10, n.19, p.103-16, jan/jun 2006.

Este estudio discute la percepción de médicos que terminaron la residencia en Obstetricia/Ginecología en el Instituto Fernandes Figueira, Fundación Oswaldo Cruz, en 2004, sobre esa trayectoria. La investigación constó de dos etapas, observación participante y construcción de fuentes orales. Fue elaborada una codificación analítica cualitativa del material colectado para posterior análisis semiótico. Se busca comprender la herencia cultural enraizada en el discurso de los residentes sobre sus relaciones con y en el mundo de la salud y la enfermedad. La devaluación de la profesión, el resentimiento por la pérdida de poder del saber médico, la percepción de la medicina como negocio más que oficio, las incertidumbres por la duplicidad de papeles -alumno y profesional-, la dificultad ante el sufrimiento y la muerte son algunos de los aspectos abordados en este artículo.

PALABRAS CLAVE: internado y residencia. práctica profesional. educación médica. 